\title{
Application of Mann-Kendall in Analyzing Water Quality Data Trend at Perlis River, Malaysia
}

\author{
Mohd Saiful Samsudin", Saiful Iskandar Khalit", Hafizan Juahir", Mohd Fahmi Mohd Nasir*, Mohd \\ Khairul Amri Kamarudin", Fathurrahman Lananan ${ }^{\#}$
}

${ }^{\#}$ East Coast Environmental Research Institute, Universiti Sultan Zainal Abidin, Gong Badak, 21300 Kuala Nerus, Terengganu, Malaysia Email: saifulsamsudin294@gmail.com,saifuliskandar@unisza.edu.my,hafizanjuahir@unisza.edu.my,mkhairulamri@unisza.edu.my, fathur6@gmail.com

*Faculty of Environmental Studies, Universiti Putra Malaysia, 43400 Serdang, Selangor, Malaysia Email:mfahmimnasir@gmail.com

\begin{abstract}
Trend detection of hydrologic da a is useful in the investigation of water quality parameters. In this study, thirty physicalchemical variables on water quality of Perlis River Basin were collected by Department of Environment (DOE) Malaysia from 2003 to 2007 were analyzed using the non-parametric Mann-Kendall Temporal test. Based on this study, the results acknowledged parameter variation over station due to the increasing of $\mathrm{Cr}$ concentration and reduction of COD along Perlis River Basin. Correlation coefficients were calculated to identify the strength of the linear relationship between two variables and this unveiled that DS and SS have the strongest correlation.
\end{abstract}

Keywords - environmetric; Perlis river; water quality; trend analysis; Mann-Kendall

\section{INTRODUCTION}

Rivers are vital natural resources for all life on earth especially human beings as it provides a water supply for domestic use, irrigation for agriculture, transportation and also for industrial purposed. Even though there is always been a wealth of fresh water in Malaysia, clean water supply is declining because of the rising of water pollution problems. Today, Malaysia has become an industrialized country but this cause destruction towards the environment. Effluents from the industrial areas are being discharged directly into the rivers without prior treatment. These problems become the major sources of water pollution. In addition, human activities such as the use of agriculture chemicals, soil erosion due to improperly planned development projects, uncontrolled land use activities and so on also contribute significantly to water pollution [1]-[4]. Lately, river pollution by toxic chemicals and an excessive amount of nutrients, resulting from surface water runoff, leaching from landfill sites and ground water discharges have also increased public concern towards water pollution issues. There is definitely a need to assess river water quality in consequence to the increased understanding of the importance of water quality towards public health and aquatic life [3]-[5].
Peninsular Malaysia consists of 11 states and two federal territories with Perlis being the smallest state and situated at the northwest of Peninsular Malaysia. The length of the Perlis River is approximately $11 \mathrm{~km}$ and it flows through Kangar city to up Kuala Perlis and the size of the river basin is approximately $310 \mathrm{~km}^{2}$. In spite of this, the quality of Perlis River does not reach the desired level and is much lower compared to the major rivers in developed countries which are used for recreational purpose. There has been heavy erosion at the river resulting in shallow river banks. Residents surrounding the river are also known to have deposited solid waste into the river system bringing about the highly unaesthetic scene. There is also a landfill located in Kuala Perlis where leachate flows into the water body. Squatters located around the river area have also contributed to Perlis River's pollution problems forcing a need for regular patrols or hut-to-hut checks. In addition, shrimp livestock ponds, Kangar wet market, esplanade of Perlis River, food stalls and the Kuala Perlis fisherman jetty also contribute significantly to the water pollution at Perlis River. Sources of water pollution can be categorized into a point and non-point sources. Point source pollutants refer to those easily identifiable pollutants which enter the water resource though a direct route, for example, effluent from wastewater treatment plants. Non-point source pollutants, on the other 
hand, refers to those pollutants which enter from various sources, and they are difficult to control, such as storm water runoff [6].

In this study, Mann-Kendall trend test has been applied to detect the trends of water quality data and to identify the sources of variations contributing to the pollution's problem of the Perlis River. The non-parametric test had been widely used to detect significant trends in time series. It also has the advantage that their power and significance are not affected by the actual distribution of the data. Thus, this method is highly suitable to be applied in detecting trends of skewed hydrologic time series containing outliers [6]. MannKendall's trend test method has been widely used in assessing the variability of hydrological time series [7]. The examples of earlier studies which applied Mann-Kendall's technique are trend study and assessment of surface water quality in the Ebro River [8], hydrological trend analysis due to land use changes at Langat River basin [9] and the analysis of water quality trend in Eymir Lake, Ankara [10].

\section{MATERIAL AND METHOD}

The location of this study is the Perlis River. There are more than ten tributaries within the Perlis area and Perlis River is one of the most important rivers in Perlis. Arau
River, Ngulang River, Serai River, Jernih River, Tasoh River, Jarum River, Kok Mak River and Pelarit River are the main tributaries of Perlis River. Kangar, the capital and the largest town in Perlis is also situated by the Perlis River. It has a population of 48,898 and an area of 2,619.4 ha and spread out along the Perlis River. According to the INWQS, the status of water quality at Sungai Perlis is classified as Class III. Water under Class III can be used as a source of drinking water but advanced and through water treatment process is needed. Moderately tolerant aquatic organisms can survive under this classification and is also suitable for livestock drinking needs. Fig. 1 shows the location of 11 water quality monitoring stations along the Perlis River basin manned by the Department of Environment (DOE) along the Perlis River Basin. The purpose of installing water quality monitoring stations is to monitor and observe the changes of river water quality at the particular area. Monitoring stations had been installed at Perlis River (2PS01), Arau River (2PS02), Ngulang River (2PS03), Serai River (2PS04), Jernih River (2PS05 and 2PS06), Tasoh River (2PS07), Jarum River (2PS08), Kok Mak River (2PS09), Pelarit River (2PS10) and Kechor River (2PS11). Table I shows the longitude and latitude of the water quality monitoring stations at Perlis River.

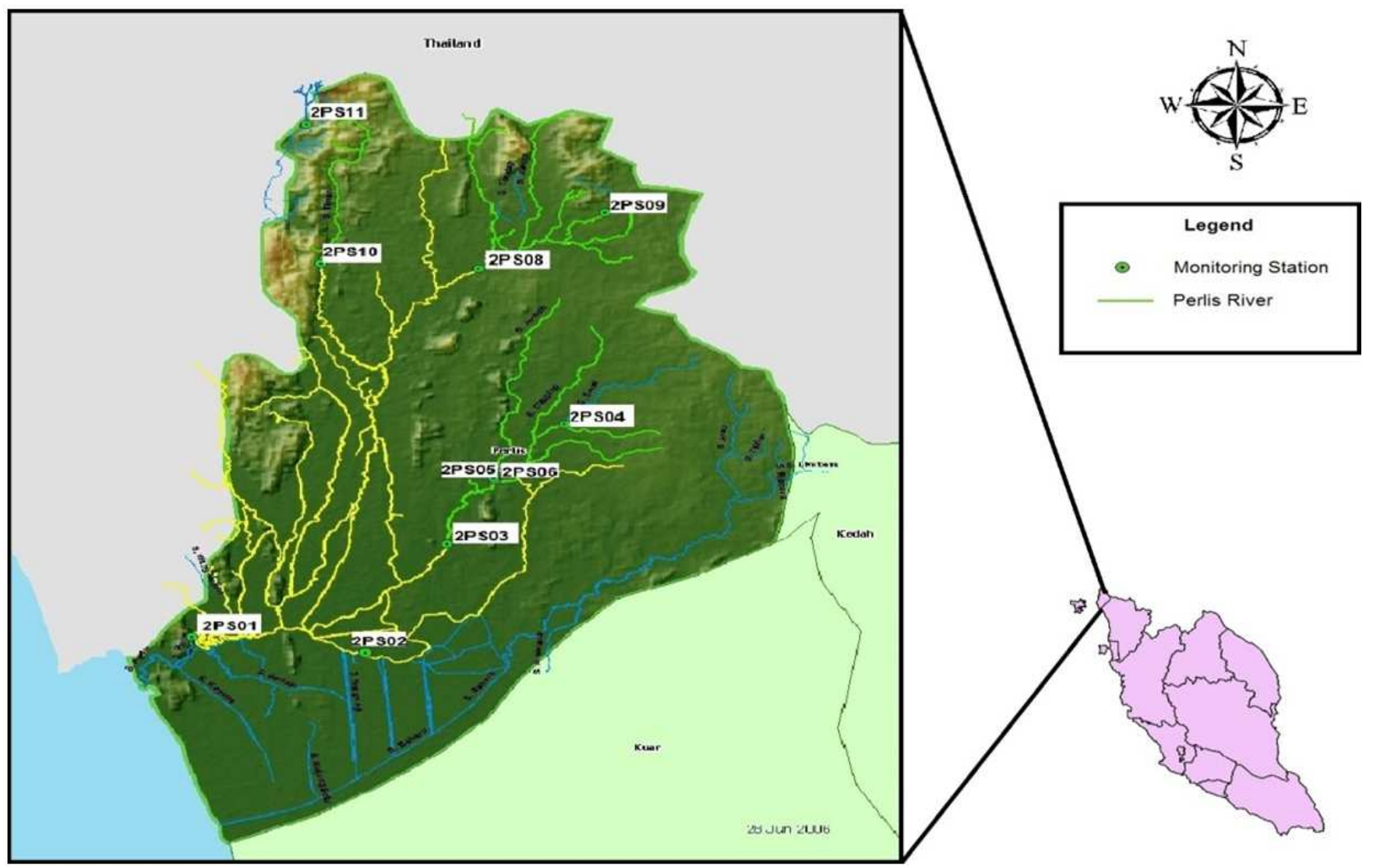

Fig. 1 Map of Perlis River with 11 water quality monitoring stations along the main river

\section{A. Data}

The data of water quality at Perlis River was obtained from 11 monitoring stations along the Perlis River is shown in Fig. 1 manned by the Department of Environment, Ministry of Natural Resource and Environment of Malaysia.
Water samples were collected for in situ and laboratory analysis to determine its physicochemical and biological characteristics. The data contained a total number of 30 parameters collected from the year 2003 until 2007. 30 water quality parameters involved in this study are, dissolved oxygen (DO), biological oxygen demand (BOD), chemical 
oxygen demand (COD), suspended [25] solid (SS), $\mathrm{pH}, \mathrm{NH}_{3}$ NL, temperature (TEMP), conductivity (COND), salinity (SAL), turbidity (TUR), dissolved solid (DS), total solid (TS), nitrate $\left(\mathrm{NO}_{3}\right)$, chlorine $(\mathrm{Cl})$, phosphate $\left(\mathrm{PO}_{4}\right)$, arsenic (As), mercury $(\mathrm{Hg})$, cadmium $(\mathrm{Cd})$, chromium $(\mathrm{Cr})$, lead $(\mathrm{Pb})$, zinc $(\mathrm{Zn})$, calcium $(\mathrm{Ca})$, iron $(\mathrm{Fe})$, potassium $(\mathrm{K})$, magnesium $(\mathrm{Mg})$, sodium $(\mathrm{Na})$, oil and grease $(\mathrm{OG})$, methylene blue active substances (MBAS), E. coli and coliform.

\section{B. Methods}

Preliminary processing (pretreatment) on the data matrix which included the reassembling the data was carried out initially. Data which were below the detection limit were complemented with values equal to half the detection limit.

There are two common types of correlation test known as Spearman rank coefficient and Pearson rank coefficient. Spearman rank coefficient may need ordinal data where its calculation will be based on the rank of data. Spearman's rank correlation coefficient is measuring on how strong the coefficient between variables in data analysis [11]. Based on the Spearman rank correlation, there are two types of correlation namely positive and negative correlations. The positive correlation shows two variables increasing together in a linear condition, whereas negative correlation shows one variable increasing and the others decreasing in a linear condition. The model obtained based on training set can be evaluated by comparing their predictions to the measured values in over fitting test set. These values are calibrated by systematically adjusting the various model parameters. The performances of the models are evaluated using the correlation of coefficients $r$ (Spearman) as follows

$$
r=\frac{\sum_{i=1}^{n}(A i-A)(\hat{A}-\hat{A})}{\sqrt{\sum_{i=1}^{n}(A i-\bar{A})^{2} \sum_{i=1}^{n}(\hat{A} i-\hat{A})^{2}}}
$$

Here, Ai and $\overline{\mathrm{A}}$ are the observed and mean values of the actual parameters time series respectively. Âi and $\tilde{A}$ are the corresponding observed and mean values of the predicted parameters time series respectively and $n$ is the number of observations [12].

\section{Mann-Kendall Trend Test}

After the data pretreatment, further analysis using the Mann-Kendall trend test were carried out according to stations and years. Mann-Kendall trend test is widely used to detect and assess the significance of a trend. In this study, Mann-Kendall trend test was used to detect the trends of water quality data at Perlis River. The test is based on the correlation between the observed parameters and their time series. The formula for Mann-Kendall trend test is defined as follows

$$
S=\Sigma_{p<q} a p q
$$

where

$$
a p q=\operatorname{sign}(x q-x p)=\operatorname{sign}(R q-R p)= \begin{cases}1 & x p<x q \\ 0 & x p=x q \\ -1 & x p>x q\end{cases}
$$

From the equation above, the $\mathrm{Rp}$ and $\mathrm{Rq}$ are the ranks of observations $x p$ and $x q$ of the time series respectively. It can be observed that the statistic test relies only on the ranks of the observations, instead of their actual values. This is the so-called distribution-free test statistic. This test is wellknown for its ability in that its power and significance are not influenced by the actual distribution of the data. In contrast, for parametric trend test such as the regression coefficient test, we can assume that the data obey to the normal distribution and its power can be greatly influenced by skewed data [13].

The mean and variance of the $\mathrm{S}$ statistic are given by the equations as shown below based on the assumption that the data set are independent and distributed as follows

$$
\begin{gathered}
E(S)=0 \\
V_{\mathrm{o}}(S)=n(n-1)(2 n+5) / 18
\end{gathered}
$$

where $n$ is the number of observations. A reduction of the variance of $S$ will be computed when the tied ranks exist in the data. The equation of $\sigma s$ is given as follows

$$
\sqrt{n(n-1)(2 n+5) / 18-\sum_{d=1}^{b} t d(t d-1)(2 t d+5) / 18}
$$

where $b$ is the number of groups of tied ranks and $t d$ is the tied observations. When the number of observations becomes large, the statistic $S$ will be normally distributed as implied as follows

$$
\mathrm{Z}= \begin{cases}\frac{(s-1)}{\sigma s} & s>0 \\ 0 & s=0 \\ \frac{(s+1)}{\sigma s} & s<0\end{cases}
$$

In this study, analysis by using Mann-Kendall trends test was applied in order to shorten the time consumption in the data. The results obtained from the Mann-Kendall trends test are then interpreted. Parameters processing which has the $p$ values smaller than 0.1 indicate that there is an existence of significant difference for that particular parameter. If the statistic $S$ shows a positive value, it is an indication there is an upward trend and if it shows a negative value, it indicates a downward trend. Instead, for the parameter which showed the p-value that greater than 0.1 , it indicates that there is no significant difference occurred for the parameter.

\section{RESULTS AND DISCUSSION}

\section{A. Correlation Study}

The correlation matrices of the 30 parameters were calculated (Spearman) and shown in Fig. 2. Due to the fact that the of 11 stations were combined in calculating the correlation matrix, the correlation coefficients should be interpreted with caution as they are affected simultaneously by spatial and temporal variations. From the figure, the clear hydrochemical relationship can be readily inferred with high and positive correlation for several parameters such as BOD, COD, SS, COND, Sal, DS, TS, Cl, Ca, K, Mg, Na, E .coli 
and coliform $(r=0.55-0.96)$. These parameters are indicative of water mineralization [9]. The correlation coefficient between DS and TS is the highest among the various correlation coefficients between other parameters (0.998). Fig. 2 shows correlation maps between 30 parameters in Blue-Red scales.

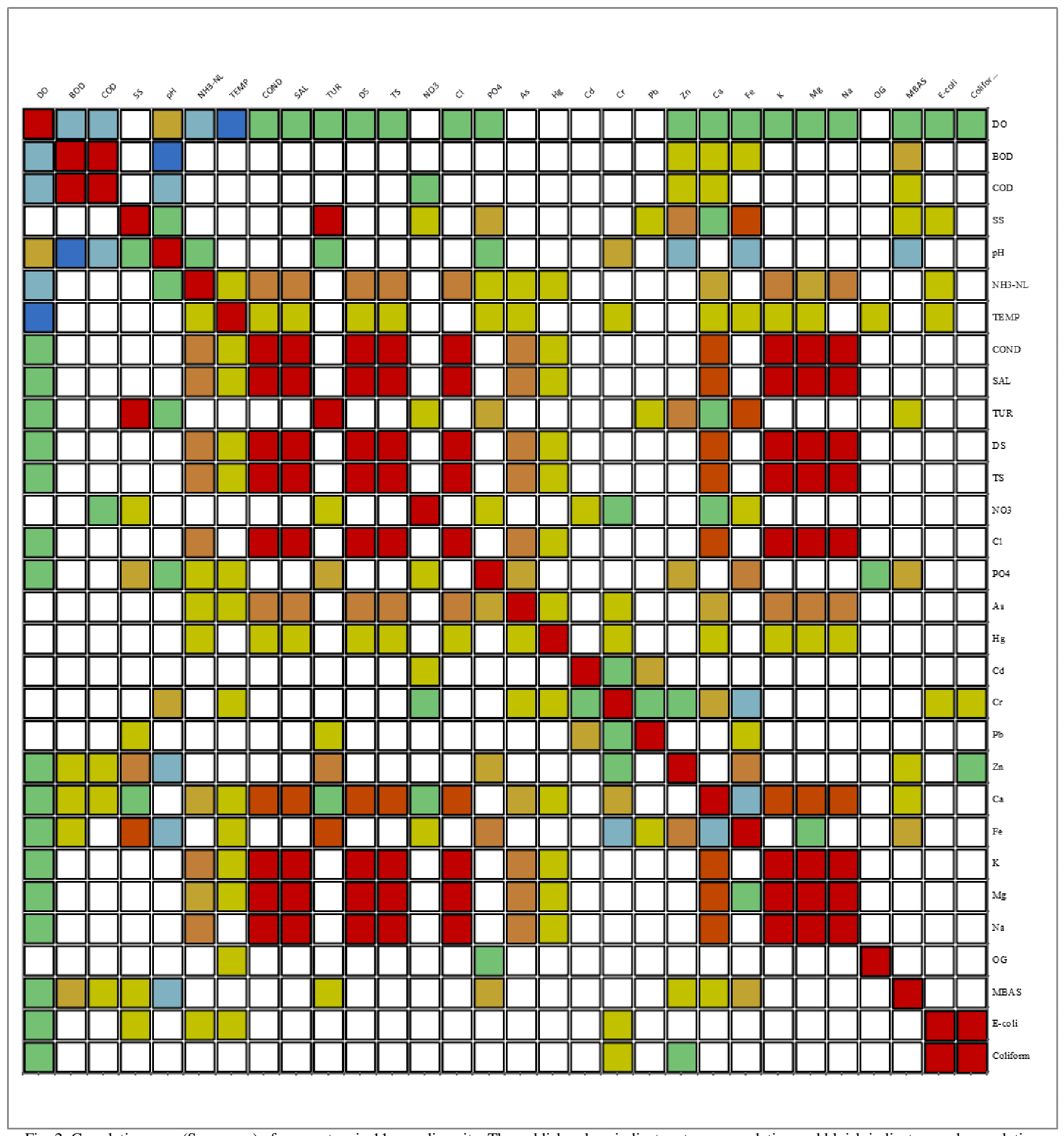

Fig. 2 Correlation map (Spearman) of parameters in 11 sampling site. The reddish colour indicates strong correlation and bluish indicates weak correlation

\section{B. Temporal Trend Analysis for Different Stations}

A trend was detected (positive or negative) quantified levels of the above-mentioned trend were found by Sen's slope [9]. The statistic $S$ which appeared in Table 1 is used to measure the trend in the data. A positive value of statistic $S$ exhibits an increase in constituent concentrations over time, whereas a negative value of statistic $S$ exhibits a decrease in constituent concentrations over time. Instead, the 'confidence level' percentage which is used to indicate the reliability of an estimate could be calculated by subtracting the probability $(p)$ from 1 (Confidence $=1-p \%)$. A confidence level of $90 \%$ represents a significance level of $\alpha$ $=0.1,95 \%$ confidence corresponds to $\alpha=0.05$ whereas $99 \%$ confidence depict a significance level of $\alpha=0.01$. A confidence level of $90 \%, 95 \%$, and $99 \%$ are applied in the 
Mann-Kendall trend test in this study. Four parameters do not have a significant variation for all stations. These are $\mathrm{BOD}, \mathrm{pH}$, temperature, of water, mercury, oil, and MBAS. $\mathrm{Cr}(90.9 \%)$ shows the highest variation throughout the studied period. The temporal variation of $\mathrm{Cr}$ for each station is shown in Fig. 3. As mentioned, $\mathrm{Cr}$ depicts a major number of detected an upward trend compared to the rest of the water quality parameters. $\mathrm{Cr}$ has the greatest degree of variation throughout the stations. Cr shows an upward trend at Station 2PS01 ( $p$-value < 0.05), Station 2PS02 ( $p$-value < 0.1 ), and at Station 2PS03 until Station 2PS10 ( $p$-value < $0.01)$. In other words, data shows $p$-value $<0.01$ indicate that the parameter $\mathrm{Cr}$ experienced a significant upward trend from the Station 2PS03 to Station 2PS10. The result of Mann-Kendall trend test for $\mathrm{Cr}$ shows no trend at Station 2PS11 yet there is a positive value of 15 is observed for Statistic S. The positive value of Statistic $S$ indicated that there is a tendency for parameter $\mathrm{Cr}$ to show an upward trend at Station 2PS11 in future if there is no any precaution step taken in controlling and improving the river water quality at the particular station. The Mann-Kendall trends test is less affected by the outliers in a dataset because its statistic is based on the sign of differences, not directly on the values of random variables [14]. Therefore, Mann-Kendall trends test shows no significant trend but the graph shows an upward trend.

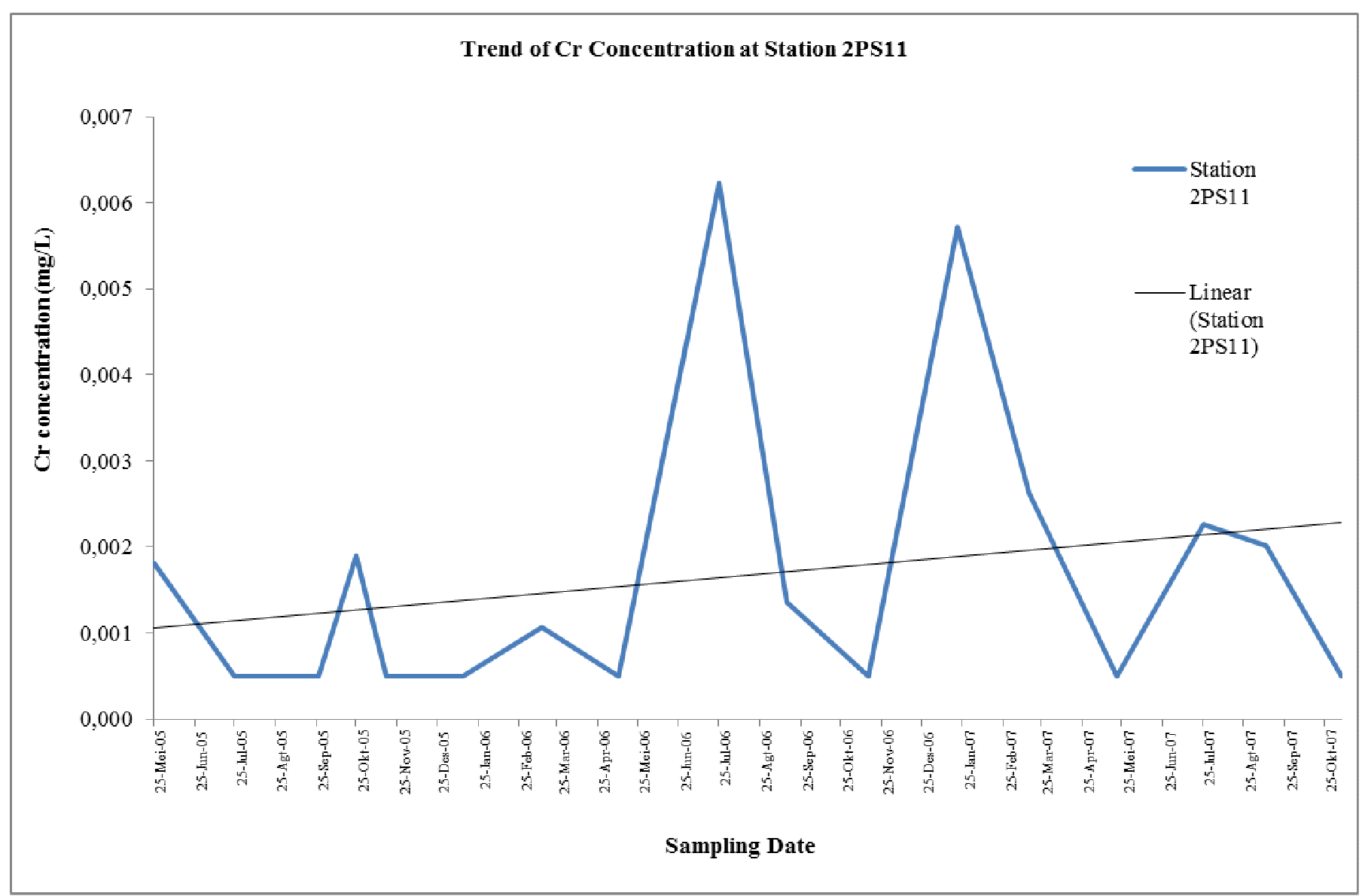

Fig. 3 Trend of $\mathrm{Cr}$ concentration at Station 2PS11

In addition, the evolution of parameter $\mathrm{Cr}$ from Station 2PS01 to Station 2PS11 could be observed through the graphical representation by using box plots (Fig. 4). The individual points beyond the whiskers are the outliers which exist in the data [15]. Cr can be considered as a pollutant specifically comes from industrial wastes, resulting from dying or paint operations [16]. According to [17], the reason for the $\mathrm{Cr}$ pollution incidents within the study period is unclear. Initially, $\mathrm{Cr}$ is a specific pollutant that provides evidence of the industrial pollution activities such as dyeing or paint operations. According to [18], the electroplating and textile industry is relatively large amounts of $\mathrm{Cr}$ released into surface waters. Leaching of soil and rock is the most vital natural source of $\mathrm{Cr}$ in the input water. Solid waste from processing plants chromate, when are improperly disposed of in landfills can be a source of contamination of the groundwater, the residence time of $\mathrm{Cr}$ may be several years. Box and whisker plots (Fig. 4) shows that stations 2PS02 and 2PS11 have the lowest mean, minimum, maximum and maximum-minimum ratio of $\mathrm{Cr}$ concentration compared to other stations. The Mann-Kendall trends test result showed no trends at stations 2PS02 and 2PS11, but significant increments are detected at other stations. According to [19], anthropogenic activities such as tanning, painting, steel works, plating, corrosion control and so forth will significantly impact the water quality. 


\section{Box and whisker plots of $\mathrm{Cr}$ concentration}

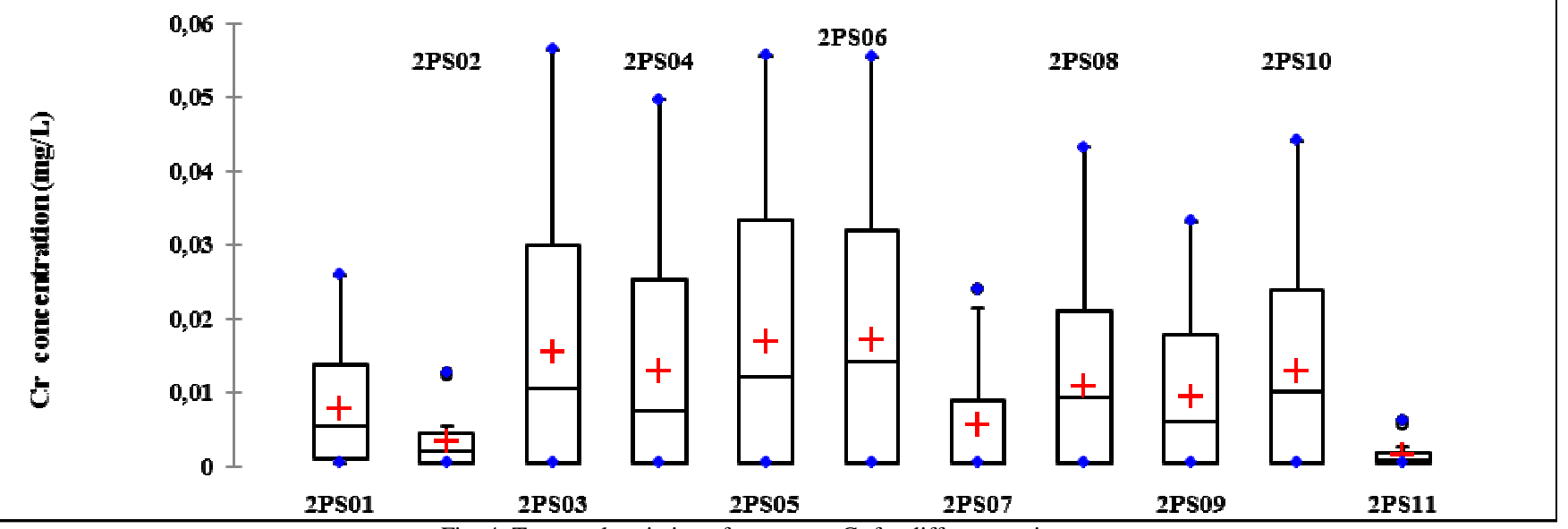

Fig. 4 Temporal variation of parameter $\mathrm{Cr}$ for different stations

Conversely, for the water quality data which shows variation according to years or in the other words temporal variations, $42 \%$ of the cases are not detected at all the years. There are $21 \%$ of upward trends have been detected from the year 2003 until 2007 and downward trends in 37\%. The parameters such as Cond (100\% of the years), Sal (100\% of the years), DS (100\%), TS (100\%) and coliform (100\%) has leaped out as the parameters which presented the major number of detected trends. Besides that, parameters such as E. coli $(60 \%$ of the years), Fe $(60 \%)$, SS $(60 \%)$, DO (60\%), Tur $(40 \%)$ and MBAS (20\%) show a significant upward trend. Meanwhile, parameters such as Cond $(100 \%$ of the years), Sal (100\%), DS (100\%), TS (100\%), Na (80\%), Mg (60\%), As $(60 \%), \mathrm{Cl}(60 \%), \mathrm{K}(40 \%), \mathrm{COD}(40 \%), \mathrm{pH}$ (40\%), BOD (20\%), NH3-NL (20\%) and Hg (20\%) show a significant downward trend. Detection of downward trends for these parameters indicates that there is an improvement of river water quality at Perlis River. From the result, there is some actions have been taken in improving river water quality by a government agency such as DOE and Department of Drainage and Irrigation. In addition, there are parameters which show two opposite trends such as coliform (100\% of the years), $\mathrm{Ca}(80 \%), \mathrm{Pb}(80 \%), \mathrm{Zn}(60 \%), \mathrm{Cr}$ (60\%), Cd (60\%), PO4 (60\%), Temp (40\%) and NO3 (40\%). The remaining parameter which is OG has shown no trend from the year 2003 until 2007. Cond, Sal, DS, TS and coliform stand out as the parameter which has the greatest amount of detected trends throughout the studied period. Parameter Cond and Sal have shown a significant downward trend from the year 2003 until 2007. Both of the parameters are correlated with each other and thus when there is a downward trend is detected for parameter Sal, a downward trend would appear for parameter Cond as well. The relationship between parameter Cond and Sal can be proved by using the correlation plot. Fig. 5 shows that parameter Cond and Sal have a strong positive linear correlation and it is exactly a perfect fit since the $R$ value $(0.9977)$ is approximately to 1 .

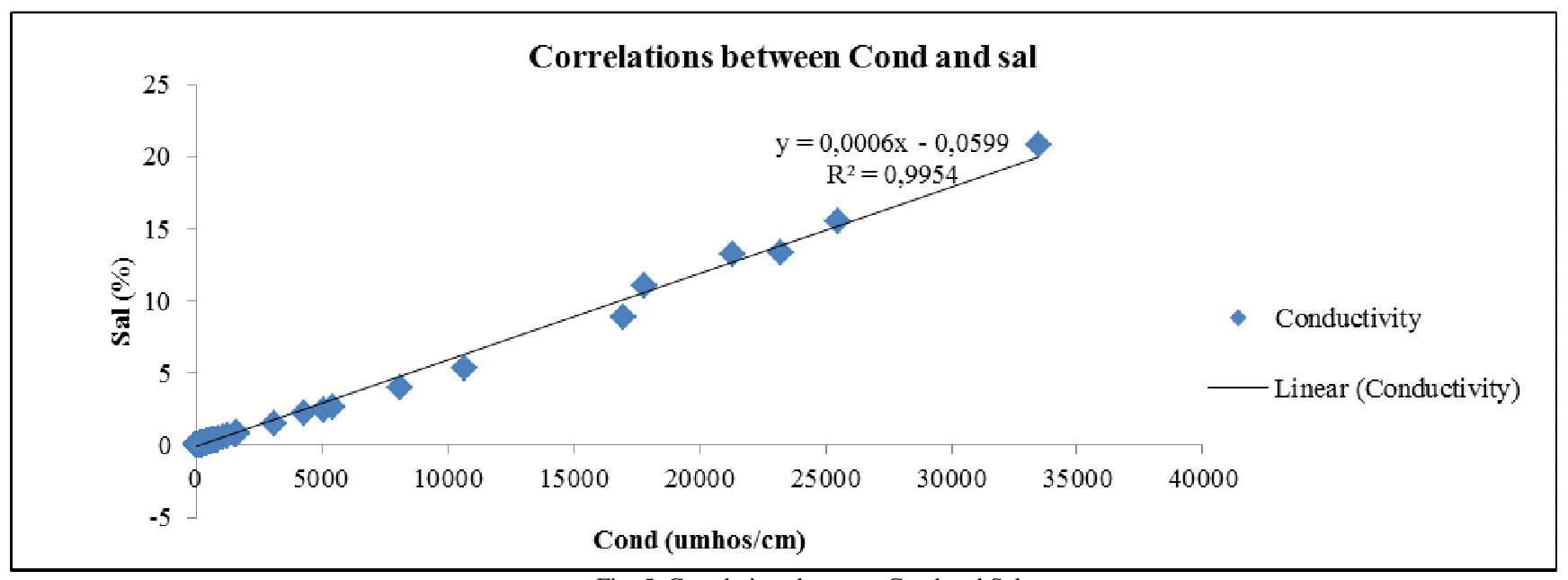

Fig. 5 Correlations between Cond and Sal

Parameter Cond and Sal experienced a significant downward trend throughout the five years are possibly due to the reduction in charged ions which appeared in the water body. Mineral soils along the river bank contain a huge amount of charged ions which are help in conducting the electricity. When there is less precipitation, soil erosion which usually leads to washing down the charged ions into the water body would be lesser. Therefore, Sal which used to measure the charged ions will be decreased and it will affect the concentration of Cond directly. 
Meanwhile, parameter DS and TS also show the greatest amount of downward trends from the year 2003 until 2007. Parameters DS is closely related to parameter TS as shown in Fig. 6. We can observe that parameter DS and TS have a strong positive linear correlation. Therefore, a decrease in DS will lead to a decrease in TS as well. Besides, correlation of coefficient $\AA$ shows a value of 0.9991 which is approximately to 1 and it is considered as a perfect fit for both parameters.

Detection of downward trends for parameters DS and TS in five particular years may due to a better waste management has been implemented around the river area. Total solids not only included SS but also DS such as the mineral ions $\mathrm{Ca}, \mathrm{P}, \mathrm{Fe}, \mathrm{S}$, and bicarnonate. A reduction in domestic waste which discharged into the water body has significantly reduced the amount of TS and DS as well.
Thus, downward trends are shown for both parameters. Coliform $(100 \%)$ is the parameter which shows two opposite trends during the studied period. A significant upward trend (p-value < 0.01) is detected at year 2003 and year 2007, upward trend (p-value < 0.05) is detected at year 2004 and year 2006, whereas significant downward trend ( $p$-value < 0.01 ) is detected at year 2005. The distribution of coliform concentrations from the year 2003 until 2007 has illustrated in Fig. 7. The box and whisker plot (Fig. 7) reveals that year 2005 had the lowest mean, minimum, maximum, and maximum-minimum ratio of coliform concentration whereas the year 2007 had the highest mean, minimum, maximum and maximum-minimum ratio. For the other years such as the year 2003, 2004, 2006 and 2007, it shows a significant increment.

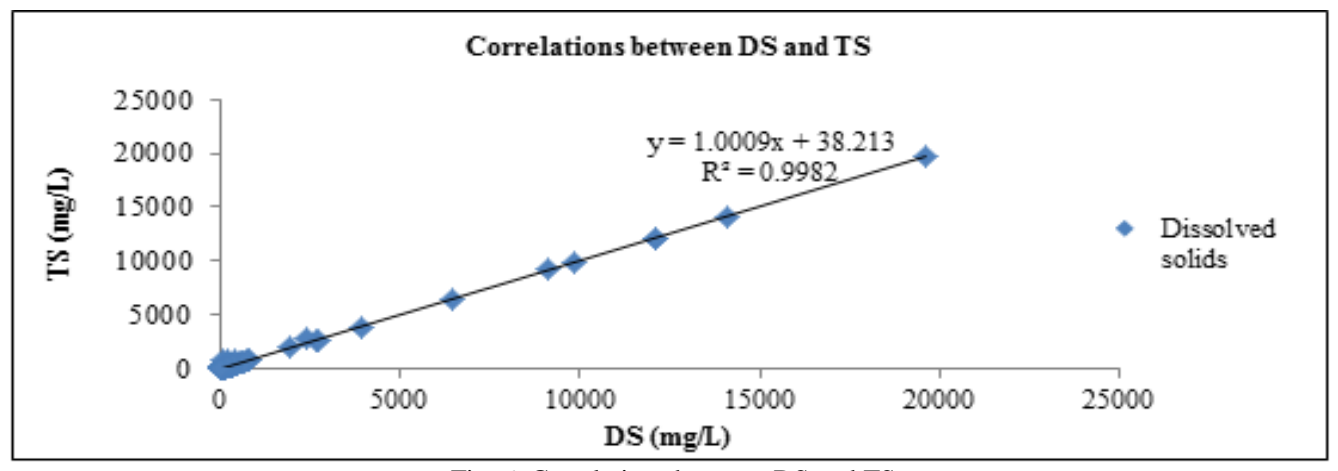

Fig. 6 Correlations between DS and TS

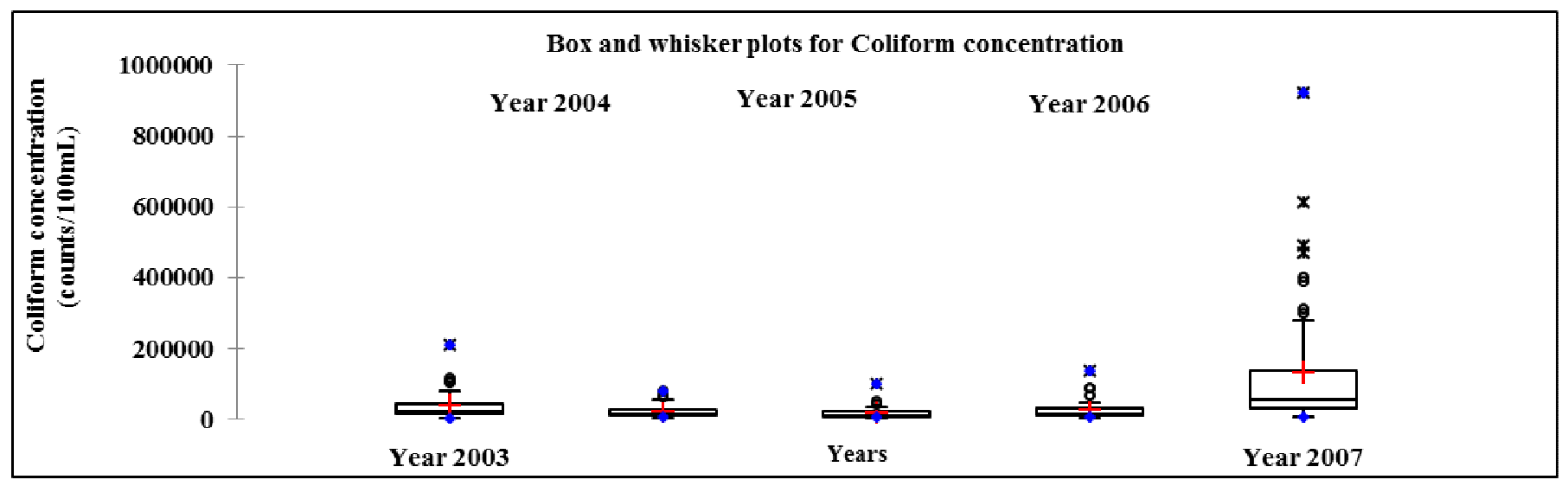

Fig. 7 Temporal variation of parameter Coliform

Surface and groundwater [26] contamination with coliform can be attributed to the surface runoff through urban areas and meadow, disposal of sewage and so on [20][24]. Therefore, a significant upward trend for coliform at Perlis River at the year 2003, 2004, 2006 and 2007 is possibly due to the domestic waste or municipal sewage which discharged by the residents at the urban areas such as Kangar. Meanwhile, the significant descent of coliform concentration at the year 2005 may due to the reduction of total disposal wastes or in the other words the implementation of a proper waste management which could help to reduce the total wastes that discharged into the water body.

As overall, the result of spatial trends analysis shows $\mathrm{Cr}$ experienced the greatest degree of variation while for the temporal trends analysis, a total number of five parameters such as Cond, Sal, DS, TS, and coliform have the greatest amount of detected trends. Besides, there is a higher variation for water quality data if compared with the spatial trends analysis which depicts a lower variation of data. For the spatial trends analysis, the result shows that parameters such as BOD, pH, Temp, Hg, Pb, OG and MBAS exhibited no trend. While for the result of temporal trends analysis, it shows that only parameter OG exhibited no trend. It may due to the development around the Perlis River at recent years and thus contributed to the high variability of river water quality data for temporal trends analysis. Hence, human activities are significantly related to the water quality as it will affect the water quality at Perlis River. 


\section{CONCLUSION}

Water quality data from 11 monitoring stations at Perlis River has been statistically analyzed. Temporal trend analysis using Mann-Kendall's trends test revealed that $\mathrm{Cr}$ manifests the most variation in all the stations studied. No trend of $\mathrm{Cr}$ is observed at Station 2PS02 and 2PS11 whereas the other stations showed strong $\mathrm{Cr}$ upward trends. The increment of $\mathrm{Cr}$ concentration at Perlis River incidents within the study period is pretty unclear. This parameter needs to investigate on the next research. It is also observed that coliform exhibit temporal upward trend throughout the study period. High variation of coliform at Perlis River may be ascribed to the surface runoff of municipal sewage or domestic waste. Urban areas such as Kangar and various agriculture activities are expected to contribute strongly to this problem.

In a nutshell, the methods applied in this study are successful in the assessment of water quality trends and pollution sources of the Perlis River. In the Malaysian scenario, the abundance of historical data should be taken into consideration in future research or in any planned monitoring program. The knowledge obtained from these data will help in designing new sampling strategies, which local authorities or government in developing a better river basin management. The use of statistical methods and trend analysis should be encouraged in the analysis of the data, which can bring about additional information and will prove to be useful in reducing cost and time of sampling. Thus, this method demonstrated would help tremendously in the future river water quality monitoring program.

\section{ACKNOWLEDGMENT}

The authors acknowledge East Coast Environmental Research Institute Universiti Sultan Zainal Abidin (UNISZA) for giving us permission to utilize the research facilities, advice, guidance, and support for this study.

\section{REFERENCES}

[1] G. J. Niemi, P. Devore, N. Detenbeck, D. Taylor, and A. Lima, "Overview of case studies on recovery of aquatic systems from disturbance," Environmental Management, vol 14, pp. 571-587, Sep. 1990.

[2] M. K. A. Kamarudin, M. E. Toriman, M. H. Rosli, H. Juahir, N. A. A. Aziz, A. Azid, S. F. M. Zainuddin, and W. N. A. Sulaiman, "Analysis of meander evolution studies on effect from land use and climate change at the upstream reach of the Pahang River, Malaysia," Mitigation and Adaptation Strategies for Global Change, vol. 20, pp. 1319-1334, Dec. 2015.

[3] A. Ismail, M. E. Toriman, H. Juahir, S. M. Zain, N. L. A. Habir, A. Retnam, M. K. A. Kamaruddin, R. Umar, and A. Azid, "Spatial assessment and source identification of heavy metals pollution in surface water using several chemometric techniques," Marine Pollution Bulletin, vol.106, pp. 292-300, May 2016.

[4] A. F. Kamaruddin, M. E. Toriman, H. Juahir, S. M. Zain, M. N. A. Rahman, M. K. A. Kamarudin, and A. Azid, "Spatial characterization and identification sources of pollution using multivariate analysis at Terengganu River Basin, Malaysia,” Jurnal Teknologi, vol 77, pp. 269-273, Oct. 2015

[5] Y. Ouyang, "Evaluation of river water quality monitoring stations by principal component analysis," Water Research, vol. 39, pp. 26212635, Jul. 2005

[6] P. Jamwal, A. K. Mittal, and J. M. Mouchel, "Point and non-point microbial source pollution: A case study of Delhi," Physics and Chemistry of the Earth, vol. 12, pp. 490-499, Dec. 2011.
[7] K. H. Hamed, "Exact distribution of the Mann-Kendall trend test statistic for persistent data," Journal of Hydrology, vol. 365, pp. 8694, Feb. 2009.

[8] K. H. Hamed, "Trend detection in hydrologic data: The MannKendall trend test under the scaling hypothesis," Journal of Hydrology, vol. 349, pp. 350-363, Feb. 2008.

[9] R. Bouza-Deano, M. Ternero-Rodriguez, and A. J. FernandezEspinosa, "Trend study and assessment of surface water quality in the Ebro River (Spain)," Journal of Hydrology, vol. 361, pp. 227-239, Nov. 2008.

[10] H. Juahir, M. S. Zain, A. Z. Aris, M. K. Yusof, M. A. A. Samah, and M. Mokhtar, "Hydrological trend analysis due to land use changes at Langat River Basin," Environment Asia, vol. 3, pp. 20-31, 2010.

[11] F. Yenilmez, F. Keskin, and A. Aksoy, "Water quality trend analysis in Eymir Lake, Ankara," Physics and Chemistry of the Earth, Parts $A / B / C$, vol. 35, pp. 135-140, Dec. 2011.

[12] D. G. Altman, Practical Statistics for Medical Research, 1st ed., Florida, USA: CRC Press, 1990.

[13] S. Yue and C. Y. Wang, "Regional Streamflow trend detection with consideration of both temporal and spatial correlation," International Journal of Climatology, vol. 22, pp. 933-946, Jun. 2002.

[14] O. Bihrat and B. Mehmetcik, "The power of statistical tests for trend detection," Turkish Journal of Engineering and Environmental Sciences, vol. 27, pp. 247-251, Jul. 2003.

[15] H. Juahi, M. S. Zain, M. K. Yusoff, T. T. H. Ismail, A. M. A. Samah, M. E. Toriman, and M. Mokhtar, "Spatial water quality assessment of Langat River Basin (Malaysia) using environmetric techniques," Environmental Monitoring and Assessment, vol. 173, pp. 625-641, Feb. 2011.

[16] A. Kaushik, A. Kansal, M. Santosh, S. Kumari, and C. P. Kaushik, "Heavy metal contamination of river Yamuna, Haryana, India: Assessment by metal enrichment factor of the sediments," Journal of Hazardous Materials, vol. 164, pp. 265-270, May 2009.

[17] C. Neal, C. J. Smith, H. A. Jeffery, M. Harrow, and M. Neal, "Dissolved chromium. pollution in rainfall and surface waters in mid-Wales during the mid-1980s," The Science of the Total Environment, vol. 188, pp. 127-138, Oct. 1996.

[18] Z. Ismail, "Monitoring trends of nitrate, chloride and phosphate levels in an urban river," International Journal of Water Resources and Environmental Engineering, vol. 3, pp. 132-138, Aug. 2011.

[19] J. W. Ball and J. A. Izbicki, "Occurrence of hexavalent chromium in groundwater in the Western Mojave desert, California," Applied Geochemistry, vol. 19, pp. 1123-1135, Jul. 2004.

[20] M. K. A. Kamarudin, M. E. Toriman, N. H. Sulaiman, F. M. Ata, M. B. Gasim, A. Muhamad, W. A. Yusoff, M. Mokhtar, M. A. Amran, and N. A. A. Aziz, "Classification of tropical river using chemometrics technique: Case study in Pahang River, Malaysia," Malaysian Journal of Analytical Sciences, 19, pp. 1001-1018, 2015.

[21] M. K. A. Kamarudin, M. E. Toriman, M. H. Rosli, H. Juahir, R. Umar, N. H. Sulaiman, F. M. Ata, A. D. Mustafa, M. A. Amran, W. A. Yusoff, and F. Azaman, "Assessment of river plan change using RS and GIS technique," Jurnal Teknologi, vol. 76, pp. 31-38, Aug. 2015.

[22] M. E. Toriman, M. K. A. Kamarudin, T. Sansena, K. Bhaktikuld, R. Umar, A. Muhamad, N. A. A. Aziz, and N. H. Sulaiman, "Assessment of land use change and sedimentation modelling on environmental health in tropical river," Malaysian Journal of Analytical Sciences, vol. 19, pp. 1335-1347, 2015.

[23] M. E. Toriman, F. M. Ata, M. K. A. Kamarudin, and M. Idris, "Bedload sediment profile and effect of river bank erosion on river crosssection," American Journal of Environmental Sciences, vol. 6, pp. 292-300, Jul. 2013.

[24] A. A. Mohamed, S. A. Rahim, D. A. Aitman, and M. K. A Kamarudin, "Analysis of seasonal soil organic carbon content at Bukit Jeriau Forest, Fraser Hill, Pahang," Malaysian Journal of Analytical Sciences, vol. 20, pp. 452-460, 2016.

[25] N. A. Wahab, M. K. A. Kamarudin, M. B. Gasim, R. Umar, F. M. Ata, and N. H. Sulaiman, "Assessment of total suspended sediment and bed sediment grains in upstream areas of Lata Berangin, Terengganu," International Journal on Advanced Science, Engineering and Information Technology, vol. 6, pp. 757-763, Oct. 2016.

[26] M. G. Abdullahi, M. K. A. Kamarudin, M. E. Toriman, M. B. Gasim, A. Endut, and I. Garba, "Assessment of natural groundwater recharge in Terengganu, Malaysia," International Journal on Advanced Science, Engineering and Information Technology, vol. 6, pp. 781786, Oct. 2016. 